\title{
Quantitative PCR and RT-PCR in Virology
}

\author{
Massimo Clementi, Stefano Menzo, Patrizia Bagnarelli, Aldo Manzin, Anna Valenza, and \\ Pietro E. Varaldo
}

Institute of Microbiology, University of Ancona, I-60100 Ancona, Italy

I

$\mathrm{n}$ the last few years, molecular hybridization methods have been used extensively in basic and applied virology because of their technical flexibility and high specificity. Using these techniques, the detection of DNA and RNA viruses directly from clinical specimens, the analysis of the specific transcriptional activity of viral genes in vitro and in vivo, and the study of virus-host relationships have all been carried out at the molecular level. However, although these methods are efficient for many purposes, only development ${ }^{(1)}$ and optimization $^{(2)}$ of PCR amplification have dramatically improved sensitivity. Currently, PCR is the method of choice for the detection of viral nucleic acids present at very low amounts in biological samples, and it allows the molecular study of most acute and persistent viral infections.

Impressive achievements that are rapidly emerging from the application of PCR to virology have also indicated that quantitative evaluation of the target sequence is necessary in several cases. In particular, methods for viral nucleic acid quantitation seem to be important, both in measuring the level of viral activity in most persistent human infections and in assessing the efficacy of specific compounds active at different steps of the viral replication cycle in vivo and in vitro. Accordingly, in the last few years, several strategies and protocols based on different methodological and technical approaches have been adopted for the semiquantitative or quantitative analysis of viral nucleic acids.

This review will focus on the strategies proposed for viral nucleic acid quantitation using PCR and reverse transcription (RT)-PCR, and the applications of these methods in basic and diagnostic virology.

\section{THE IMPACT OF PCR AMPLIFICATION IN VIROLOGY}

Since the development of PCR amplification, one of the major applications of this method has been the highly sensitive and direct detection of viral nucleic acids in clinical samples. ${ }^{(3)}$ A great deal of new information has been obtained rapidly using this approach in most viral infections, thus allowing more precise pathogenic, diagnostic, and epidemiological studies.

In particular, PCR-based techniques have successfully been applied to address the following three main virological aspects. First, because of its sensitivity and rapidity, PCR amplification has made the molecular diagnosis of viral infections easier, faster, and more accurate. ${ }^{(3-6)}$ Also, PCR has enabled etiological and pathogenetic hypotheses to be tested efficiently, ${ }^{(7,8)}$ and novel strategies to identify unknown or uncharacterized viruses have been planned and optimized. ${ }^{(9)}$ From a diagnostic point of view, reliable and sensitive methods for detecting viremia during the course of several persistent viral infections [including forms from major viral pathogens of humans, such as hepatitis B virus (HBV), ${ }^{(5,6,10)}$ human immunodeficiency virus type 1 (HIV-1), ${ }^{(11)}$ and hepatitis C virus $\left.(\mathrm{HCV})^{(12)}\right]$ have now become available.

Second, the use of RT-PCR has led to the highly sensitive detection and analysis of the viral transcriptional activity in vivo and in vitro. In particular, an accurate assessment of viral activity may be critical to the precise understanding of either the pathogenetic steps involved in the onset and development of most viral diseases or in viral tissue tropism. These important aspects have been investigated directly using qualitative RT-PCR methods that allow qualitative detection of specific viral mRNAs, as in the cases of HIV-1 ${ }^{(13-15)}$ and HBV infections. ${ }^{(16,17)}$

Third, because PCR amplification supplies templates pure enough to be analyzed directly using standard sequencing protocols, this method enables viral mutants to be detected directly, thus avoiding the use of molecular cloning procedures. The potential impact of this technical improvement in virology might be revolutionary, because several lines of evidence indicate the increasing need for fast and easy laboratory procedures to sequence viral DNAs and CDNAs amplified from clinical samples on a large scale. In fact, although other virological fields will probably be explored using this methodology in the near future, the precise detection of mutants generated and selected (escape mutants) during several viral persistent infections might be critical for a correct laboratory diagnosis. The precore-defective variants frequently generated during persistent HBV infection ${ }^{(18,19)}$ and associated with ongoing liver disease, and viral variants selected during treatments ${ }^{(20)}$ and resistant in vivo to specific antiviral compounds, may be involved in this aspect.

Recently, increasing evidence has shown that the molecular study of most viral infections in vivo requires absolute quantitation. In fact, it has been observed that insufficient information on the level of viral gene expression, tissue tropism, and virus-host relationships is provided by qualitative assays that indicate the presence or absence of specific viral nucleic acids in tissues or plasma samples. Although the biological diversity of viral pathogens and the pathogenic and clinical complexity of individual viral infections may generate specific diagnostic problems, different clear examples of general interest have been 
supplied by several groups and these examples indicate that not only qualitative but also quantitative molecular data are necessary in basic and medical virology.

In fact, PCR analysis of HIV-1 infection in vivo has unambiguously indicated that (1) proviral DNA sequences, ${ }^{(21)}$ (2) viral specific transcripts in $\mathrm{CD}^{++}{ }^{+} \mathrm{T}$ lymphocytes, ${ }^{(11,22)}$ and (3) HIV-1 genomic RNA sequences in plasma samples ${ }^{(11)}$ are detectable in virtually all HIV-1-infected individuals, regardless of the presence of clinical symptoms and the fall in $\mathrm{CD}^{++}$peripheral blood lymphocyte levels. Because pathogenic investigation of this human infection has revealed that the increasing viral burden is strictly associated with the progressive immunosuppression and the onset and development of clinical disease, ${ }^{(23)}$ quantitation of the HIV-1 activity levels is critical to the precise understanding of the natural history of this infection. Attempts to quantify the HIV-1 burden initially were made by using virus isolation and $50 \%$ tissue culture infective dose titers $\left(\mathrm{TCID}_{50}\right)$ analysis. ${ }^{(24)}$ However, although improved sensitivity of HIV-1 isolation methods have recently been reported, ${ }^{(25)}$ they may probably be highly imprecise from a quantitative point of view, because reproducibility of these assays is dependent on numerous variables.

Moreover, by studying persistent $\mathrm{HBV}$ infection, it has been observed that the amount of viral DNA in plasma samples from $\mathrm{HBV}$ chronic carriers is a direct index of active viral replication in liver cells and that this molecular parameter is correlated with liver disease progression. PCR analysis of $\mathrm{HBV}$ viremia in samples from asymptomatic and symptomatic $\mathrm{HBV}$-infected patients has been carried out extensively; these studies have indicated that a significant proportion of these patients are viremic, $(4,10,26)$ thus suggesting that quantitative methods for the precise evaluation of $\mathrm{HBV}$ DNA levels in serum may be important in the pathogenic and clinical investigation of HBV liver diseases. Similarly, it has recently been suggested that the natural history of HCV infection might correctly be studied using quantitative PCRbased methods for HCV RNA detection in serum or plasma samples. ${ }^{(27)}$

Finally, all long-term treatments with specific antiviral compounds active at different steps of the replication cycle of patients with persistent viral infections require reliable quantitative monitoring of the viral burden in vivo.

\section{STRATEGIES FOR QUANTITATIVE PCR}

A linear relationship has been observed to exist between the input template and the amount of amplification product $^{(28-30)}$ in PCR assays. Accordingly, methods have been proposed for the simple quantitation of the amplification product. $^{(31-33)}$ However, since the amount of final reaction product depends on exponential amplification of the initial DNA copy numbers, minor differences in amplification efficiency may lead to very large and unpredictable differences in the final product yield. In particular, tube-to-tube differences may depend on sample preparation and nucleic acid purification procedures, the presence of inhibitors, and machine performance. As a consequence, especially if the amount of the initial template is small, any differences generated during the first PCR cycles may dramatically influence the quantitative analysis of reaction products. For these reasons, although the PCR analysis of a given sequence using an external standard reference curve prepared for each experiment may be simple and fast in theory, the unpredictable variability of individual amplification reactions does not allow reliable nucleic acid quantitation using this methodology.

The assay of limiting dilutions of samples using $\mathrm{PCR}^{(34-36)}$ was first proposed to obtain semiquantitative results. This conceptually simple strategy presents several degrees of risk in practice. In fact, because the above-mentioned linear relationships between the initial amount of template DNA and the amplification product are only maintained for amounts of starting $\mathrm{DNA}^{(37)}$ lying within a limited range, a dilution method may be very imprecise when samples containing highly variable amounts of target DNA are examined. Furthermore, because many PCR reactions per sample are necessary to quantitate the amount of the target sequence by the Poisson distribution analysis of positive reactions, this approach is expensive, time-consuming, and of limited application when analyzing a large number of samples.

More recently, to control tube-to-tube variability in PCR reactions, an alternative method using coamplification of internal reference templates has been used. In this case, either a single-copy cellular gene ${ }^{(38,39)}$ or a ubiquitously expressed transcript ${ }^{(40)}$ is coamplified with the target sequence, thus overcoming the problem of tube-to-tube variations. The rationale supporting this technique is that any of the variables influencing the amplification efficiency should affect both templates similarly. In this case, a major problem is that different PCR templates may have highly different thermodynamics and amplification efficiencies, thus influencing the relative amounts of products. Consequently, although the amplification parameters for each primer set may be optimized empirically, the different nature of the template sequences might influence the amount of both products in this coamplification unpredictably. (Thus, in this respect, this method is in partial contrast with the PCR theory.) Additionally, a further limit of this procedure in virological applications is that it cannot be used in the quantitative detection of extracellular template species, such as free viruses in plasma samples.

For these reasons, attempts have been made to develop other PCR-based strategies for nucleic acid quantitation. One of these methods is competitive PCR (cPCR). ${ }^{(41)}$ In this technique, the reference template (sharing the primer recognition site with the target sequence) is coamplified with the target template to be quantified.

Several lines of evidence have suggested that this approach is presently the most reliable for nucleic acid quantitation using PCR and RT-PCR. Also, several applications have confirmed its high level of precision and flexibility, and different types of competitors and different methods for obtaining a more accurate quantitation of the target sequence have been proposed. Thus, a separate discussion of all these aspects is necessary.

\section{THE COMPETITIVE APPROACH}

The general concept of $\mathrm{CPCR}^{(42)}$ is the coamplification in the same tube of two different templates of equal or similar lengths and with the same primer recognition sequences, thus ensuring identical thermodynamics and amplification efficiency for both template species. The amount of one of the templates introduced must be known. After amplification, products of both template species 
must be clearly distinguishable by gel electrophoresis analysis to allow densitometric evaluation of the relative intensities of the bands for both species.

Because the templates compete for amplification (and, in the case of competitive RT-PCR, also for reverse transcription), any variable affecting amplification has the same effect on both. As a consequence, the ratio of PCR products (which may be calculated using spectrophotometric analysis of gels) reflects the ratio between the initial amount of the two sequences, thus allowing the precise evaluation of the amount of wild-type template. In fact, according to the principle of PCR amplification, product yield follows the well known function $Y=Y^{\prime}$. $(1+e)^{n}$ and it directly depends on the starting template copy numbers $\left(Y^{\prime}\right)$, amplification efficiency $(e)$, and number of cycles $(n)$. In competitive PCR, this function is written for both templates as follows: competitor DNA $=C=C^{\mathrm{i}}$. $(1+e)^{n} \quad$ wild-type $\quad$ DNA $=W=W^{i}$. $(1+e)^{n}$ where $C$ is the amount of competitor DNA obtained, $C$ is the initial amount, $e$ is the efficiency of amplification, and $n$ is the number of cycles; similarly, $W$ is the amount of wild-type DNA obtained, and $W^{i}$ is the initial amount.

Since the $e$ and $n$ are identical for both templates in $\mathrm{CPCR}$, the relative product ratio $(\mathrm{C} / \mathrm{W})$ directly depends on their initial concentration as demonstrated by the function: $C / W=C^{\text {i }}$. $(1+e)^{n} / W^{\mathrm{i}} \cdot(1+e)^{n}=C^{\mathrm{i}} / W^{\mathrm{i}}$

Because the last expression is a straight line, it might be concluded that a single dilution of competitor could be sufficient in theory for quantifying unknown template species using this assay. However, because the precise analysis of two template species present in very different amounts may be difficult and imprecise in practice, competitions using three to four competitor dilutions within the expected range of wild-type molecules generally are performed. ${ }^{(43)}$

Different types of competitors have been proposed for CPCR: (1) competitors with a different length from that of the target sequence, ${ }^{(37,41,44,45)}$ (2) competitors bearing a mutation that creates a new restriction site, ${ }^{(46,47)}$ and (3) competitors separated by temperature gradient gel electrophoresis. ${ }^{(48)}$ Although the choice of the best competitor to use may depend on several factors, including laboratory experience, enzyme digestion of amplified sequences should be avoided because an additional step whose efficiency may vary is introduced in the assay. Consequently, it is preferable to use sequences directly separated by gel electrophoresis as competitors. Nevertheless, because great diversity in sequence length may give rise to differences in amplification efficiencies, it must be stressed that when planning competitors internal deletions or insertions have to be reduced to the minimum necessary to obtain discrete bands in amplification products after gel electrophoresis, thus avoiding excessive differences in size.

The steps of mutagenesis and cloning needed to construct competitors can often require much work. Recently, we used PCR to generate an internal deletion of the highly conserved HIV-1 gag sequence amplified using the SK38-SK39 primer set. ${ }^{(45)}$ The deleted sequence was obtained starting from the wild-type sequence by using a single-step, PCR-based mutagenesis; it was subsequently cloned in the pBS transcription vector. After in vitro RNA synthesis, an internally deleted (18 bases) RNA competitor to be used in the competitive RT-PCR (cRTPCR) was obtained. Similarly, rapid methods to construct DNA competitors using either PCR and site-directed mutagenesis by overlap extension ${ }^{(37)}$ or amplification of two fragments whose subsequent ligation supplies an internally truncated competitor ${ }^{(43)}$ have been described.

In CPCR and CRT-PCR, the ratio of amplified products reflects the initial concentration of both template species, regardless of the total amounts produced by the amplification reaction. As recently demonstrated, ${ }^{(37)}$ this principle is of basic relevance when the amount of a given sequence has to be estimated from different sample preparations (such as preparations from clinical specimens). As a direct consequence, cPCR and cRT PCR results do not depend on the number of amplification cycles, and generation of nonspecific amplification products (frequently observed in PCR amplifications using genomic DNAs) does not influence the ratio of specific products.

Amplification products can be visualized and quantified directly after simple ethidium bromide staining. Densitometric evaluation of ethidium bromidestained gels makes the final step easier, faster, and more direct than using Southern hybridization. In fact, gels may be scanned using a densitometer either directly (by positive fluorescent emission on the transilluminator) or after photography (Fig. 1). The peak areas of both amplified products may be calculated, but, when a deleted competitor or a competitor with a small insertion is used, the corresponding value has to be corrected for the different levels of molar ethidium bromide incorporation. ${ }^{(45)}$ Finally, the ratio of both values may be plotted against the competitor copy numbers used in the assay (Fig. 1).

Similar to other qualitative and quantitative molecular assays, the DNA/RNA purification procedure is the only step that is not controlled in the competitive assay. This may be important in diagnostic applications of these methods in which samples from different origins are employed. However, competitive methods allow the mean loss of nucleic acids during the different purification procedures used for CPCR and CRT-PCR to be calculated. By using CRT-PCR, we have evaluated the effect of the procedure used to purify HIV-1 genomic RNA from plasma samples of infected subjects on template recovery: HIV-1 genome copy numbers present in clinical samples were quantified after purification, and quantified again after second reextraction of the samples assayed. ${ }^{(45)}$ Under these conditions, we estimated a mean RNA loss from the starting material of $36 \%$ due to the extraction procedure used. In our opinion, this indicates that all of the quantitative molecular results should be corrected for a mean loss specifically determined for the extraction method used.

Overall, cPCR and cRT-PCR now represent the methods of choice for the $a b$ solute quantitation of nucleic acids. Any variable affecting amplification has the same effect on both template species, and direct evaluation of ethidium bromide-stained gels is possible, thus allowing the easy analysis of the reaction products. However, it is important to note that further optimization may be necessary. In particular, the technique still requires several amplification reactions per sample, thus it is expensive and allows the analysis of only a few samples for each amplification run.

\section{APPLICATIONS OF QUANTITATIVE PCR IN VIROLOGY}

Different aspects can be investigated ef- 


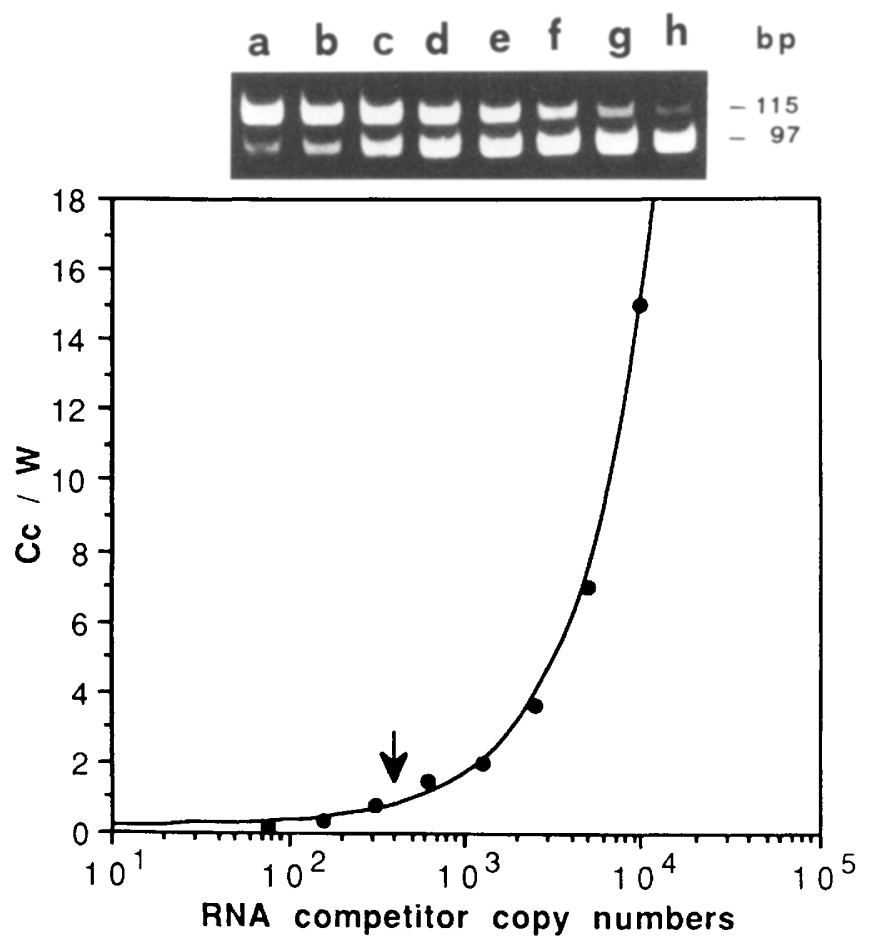

FIGURE 1 Competitive RT-PCR. A constant amount of HIV-1 genomic RNA was purified using guanidinium thiocyanate from HIV-1-infected $\mathrm{H} 9$ cell supernatant, and, subsequently, reversetranscribed and amplified along with increasing copy numbers of pSKAN RNA (lanes $a-h$, twofold increasing copy numbers of competitor RNA from 78 to 10,000). The pSKAN plasmid was obtained as described previously. ${ }^{(44)}$ The cRT-PCR was performed in two steps: cDNA was synthesized in the presence of HIV-1 genomic sequences and the competitor RNA; after reverse transcription, each amplification was carried out in a total volume of $100 \mu \mathrm{l}$ of standard PCR buffer $\left(1.5 \mathrm{mM} \mathrm{MgCl}_{2}\right)$. Fifty thermal cycles were carried out as follows: $93^{\circ} \mathrm{C}$ for $30 \mathrm{sec}, 60^{\circ} \mathrm{C}$ for $30 \mathrm{sec}$, and $72^{\circ} \mathrm{C}$ for $60 \mathrm{sec}$. The final incubation was at $72^{\circ} \mathrm{C}$ for $10 \mathrm{~min}$. The gel was scanned using a video densitometer (Ultra Violet Products Ltds., Cambridge, UK) by positive fluorescent emission on the transilluminator. Peak areas $(C$, competitor area; $W$, wild-type area) of both amplified products were calculated by the machine software (Gel Analysis Program; UVP) in each lane. The $C$ value was corrected $(C c)$ for its lower molar ethidium bromide incorporation as follows: $C c=C \cdot$ (wild-type length/deleted length) $=C \cdot 1.1855$ (in this case). The $C c / W$ ratio was calculated for each lane and plotted on the $y$ axis against the copy number of the deleted competitor. The regression curve $(y=a+b x)$ was calculated as follows: $y=0.182+0.00146 \times\left(r^{2}=0.997\right)$ and the copy numbers of the wild-type template were calculated from the curve expression for $C c / W=1$ (arrow; 562 molecules).

ficiently using a quantitative molecular approach in basic and applied virology. The two major fields to which CPCR and cRT-PCR can usefully be applied at present appear to be (1) the precise evaluation of the level of specific viral activity during persistent infections, and (2) the more correct and direct analysis of specific antiviral treatments in vivo. Other applications may be of primary importance - the faster and easier molecular screening of putative antiviral compounds in vitro, and, as a complement to other molecular methods, the accurate evaluation in vivo and in vitro of the viral tissue tropism.

Recently, for a better understanding of AIDS pathogenesis, considerable effort has been made to develop laboratory methods for the reliable, direct monitoring of viral load in vivo in the different phases of the HIV-1 infection. Proviral DNA in infected peripheral blood lymphocytes (indicating the number of infected cells), ${ }^{(23,49)}$ and cell-free HIV-1 RNA molecules in serum or plasma samples (HIV-1 viremia) ${ }^{(50,51)}$ have been assayed using different quantitative PCRbased approaches. Although quite different and uncomparable quantitative results have been reported (probably depending on the different technical strategies used), these studies have clearly indicated that direct measures of the infectious burden are necessary to follow these patients.

In this context, we have recently highlighted that a direct correlation between viral burden and clinical stage exists. ${ }^{(52)}$ In these studies, the HIV-1 infection has been investigated in vivo by using a cRT-PCR method, and quantitative data on HIV-1 viremia levels, specific viral transcript copy numbers in peripheral blood lymphocytes, and (using a cPCR) proviral molecules in samples from asymptomatic and symptomatic HIV-1-infected patients have been obtained. By using this approach, although sharp individual variability was observed, it has been found that quantitative virological parameters are strongly correlated with disease progression and the fall in $\mathrm{CD}^{++} \mathrm{T}$ lymphocyte levels. Moreover, a new indirect parameter (the RNA/DNA ratio) indicating the mean proviral transcriptional activity (average number of transcript molecules for each HIV-1 provirus) has been evaluated and correlated with clinical conditions. The study of these molecular parameters to follow the course of the natural infection is soon expected either to facilitate pathogenetic research on AIDS or to allow a more correct clinical management of these patients.

Similarly, other persistent viral infections have been studied using different quantitative PCR methodologies. As an example, the study of $\mathrm{HCV}$ infection in two experimentally infected chimpanzees by using end-point dilution RT-PCR has indicated that titers of HCV RNA in serum and liver are correlated with signs of liver damage. ${ }^{(53)}$ Accordingly, the study of HCV-infected patients (untreated and treated with interferon- $\alpha$ ) using a cRT-PCR method ${ }^{(27)}$ has recently provided further evidence that molecular quantitation also acts as a reliable and sensitive index not only for monitoring the effect of antiviral compounds in vivo, but also for both the more precise analysis of $\mathrm{HCV}$ activity and the better understanding of the molecular basis of $\mathrm{HCV}$ persistence.

\section{CONCLUSIONS}

The qualitative features of most PCR and RT-PCR assays have limited their use to applications where only the presence or the absence of a target sequence has to be determined. From this point of view, quantitative PCR-based procedures ex- 
tend the potential applications of amplification assays.

We have described recent attempts to develop quantitative PCR-based techniques and have observed that PCR and RT-PCR may now be used not only in the semiquantitative analysis of nucleic acids present in a biological sample at a very low amount, but also in the precise absolute quantitation of given DNA and RNA sequences. Additionally, time-consuming optimization and validation procedures necessary to obtain semiquantitative results using either coamplification methods or external standards $^{(54)}$ may be avoided by using the more direct and unambiguous competitive approach.

Although, at present, it is impossible to enumerate all of the potential applications of quantitative PCR-based methods, they certainly represent a concrete aid for both a more accurate experimental approach to many biological fields and a less empiric medical management of viral diseases.

\section{ACKNOWLEDGMENTS}

This work was supported by the Italian Ministero della Sanitá $\left(6^{\circ}\right.$ Progetto AIDS), and Consiglio Nazionale delle Ricerche (C.N.R.) (Progetto Biotecnologie e Biostrumentazione; BTBS).

\section{REFERENCES}

1. Saiki, R. K., T.L. Bugawan, G.T. Horn, K.B. Mullins, and H.A. Erlich. 1986. Analysis of enzymatically amplified $\beta$-globin and HLA-DQa DNA with allele specific oligonucleotide probes. Nature 324: 163-166.

2. Saiki, R. K., D. Gelfand, S. Stoffel, S.J. Scharf, R. Higuel, G.T. Horn, K.B. Mullis, and H.A. Erlich. 1988. Primer directed enzymatic amplification of DNA with a thermostable DNA-polymerase. Science 239: 487-491.

3. Ou, C.-Y., S. Kwok, S.W. Mitchel, D.H. Mack, J.J. Sninsky, J.W. Krebs, P. Feorino, D. Warfield, and G. Schoechetman. 1988. DNA amplification for direct detection of HIV-1 in DNA of peripheral blood mononuclear cells. Science 239: 295-297.

4. Garbuglia, A.R., A. Manzin, A. Budkowska, G. Taliani, M. Clementi, C. Delfini, and G. Carloni. 1991. Levels of Pre-S antigens and HBV DNA in sera from high and low viremic HBV carriers. J. Med. Virol. 35: 273-282.

5. Larzul, D., F. Guigue, J.J. Sninsky, D.H. Mack, C. Brechot, and J.-L. Guesdon. 1988. Detection of hepatitis B virus se- quences in serum using in vitro enzymatic amplification. J. Virol. Methods 29: 227-237.

6. Kaneko, S., R. Miller, S. Feinstone, M. Onoura, K. Kobayashi, N. Hattori, and R. Purcell.1989.Detection of serum hepatitis $B$ virus DNA in patients with chronic hepatitis utilizing the polymerase chain reaction assay. Proc. Natl. Acad. Sci. 86: 312 316.

7. Richardson, J.H., K.W. Wucherpfenning, N. Endo, P. Rudge, A.G. Dalgleish, and D.A. Hafler. 1989. PCR analysis of DNA from multiple sclerosis for the presence of HTLV-1.Science 246: 821-823.

8. Menzo, S., A. Manzin, P. Bagnarelli, P.E. Varaldo, G. Grandi, G. Giuliani, G. Cazzato, M. Giacca, and M. Clementi. 1992. Lack of detectasble human T-cell lymphotropic virus type I sequences in samples from multiple sclerosis patients. J. Med. Virol. 36: 155-161.

9. Mack, D.H. and J.J. Sninsky. 1988. A sensitive method for the identification of uncharacterized viruses related to known virus groups: hepadnavirus model system. Proc. Natl. Acad. Sci. 85: 6977-6981.

10. Manzin, A., G. Salvoni, P. Bagnarelli, S. Menzo, G. Carloni, and M. Clementi. 1991. A single-step DNA extraction procedure for the detection of serum hepatitis $B$ virus sequences by the polymerase chain reaction. J. Virol. Methods 32: 245253.

11. Bagnarelli, P., S. Menzo, A. Manzin, M. Giacca, P.E. Varaldo, and M. Clementi. 1991. Detection of human immunodeficiency virus type 1 genomic RNA in plasma samples by reverse-transcription polymerase chain reaction. J. Med. Virol. 34: 89-95.

12. Weinmer, A., G. Kuo, D.W. Bradley, F. Bonino, G. Saracco, C. Lee, J. Rosenblatt, Q.L. Choo, and M. Houghton. 1990. Detection of hepatitis $C$ viral sequences in non-A, non-B hepatitis. Lancet i: $1-3$.

13. Hart, C., T. Spira, J. More, J. Sninsky, G. Schochetman, A. Lifson, J. Galphin, and C.Y. Ou. 1988. Direct detection of HIV RNA expression in seropositive subjects. Lancet ii: 596-599.

14. Murakawa, G.J., J.A. Zaia, P.A. Spallone, D.A. Stephens, B.E. Kaplan, R.B. Wallace, and J.J. Rossi. 1988. Direct detection of HIV-1 RNA from AIDS and ARC patient samples. DNA 239: 295-297.

15. Bagnarelli, P., S. Menzo, A. Manzin, P.E. Varaldo, M. Montroni, M. Giacca, and M. Clementi. 1991. Detection of human immunodeficiency virus type 1 transcripts in peripheral blood lymphocytes by the polymerase chain reaction. J. Virol. Methods 32: 31-39.

16/ Paterlini, P., G. Gerken, E. Nakajima, S. Terre, A. D'Errico, W. Grigioni, B. Nalpas, D. Franco, J. Wands, M. Kew, E. Pisi, P. Tiollais, and C. Brechot. 1990. Polymerase chain reaction to detect hepatitis $B$ virus DNA and RNA sequences in primary liver cancers from patients negative for hepatitis B surface antigen. N. Engl. I. Med. 323: $80-85$.

17. Clementi, M., A. Manzin, P. Bagnarelli, S. Menzo, P.E. Varaldo, and G. Carloni. 1992. Human immunodeficiency virus type 1 and hepatitis $B$ virus transcription in peripheral blood lymphocytes from coinfected subjects. Arch. Virol. 126: 1-9.

18. Santantonio, T., M.C. Jung, S Miska, G. Pastore, G.R. Pape, and H. Will. 1991. Prevalence and type of pre-C HBV mutants in anti-HBe positive carriers with chronic liver disease in a highly endemic area. Virology 183: 840-844.

19. Manzin, A., S. Menzo, P. Bagnarelli, P.E. Varaldo, I. Bearzi, G. Carloni, F. Galibert, and M. Clementi. 1992. Sequence analysis of the hepatitis $\mathrm{B}$ virus pre- $\mathrm{C}$ region in hepatocellular carcinoma (HCC) and nontumoral liver tissues from HCC patients. Virology 188: 890-895.

20. Larder, B.A., K.E. Coates, and S.D. Kemp. 1991. Zidovudine-resistant human immunodeficiency virus selected by passage in cell culture. J. Virol. 65: 5232-5236.

21. Jackson, J.B., S.Y. Kwok, J.J. Sininsky, J.S. Hopsicker, K.J. Sannderud, F.S. Rhame, K. Henry, M. Simpson, and H.H. Balfour. 1990. Human immunodeficiency virus type 1 detected in all seropositive symptomatic and asymptomatic individuals. $J$. Clin. Microbiol. 28: 16-19.

22. Schittman, S.M., J.J. Greenhouse, H.C. Lane, P.F. Pierce, and A.S. Fauci. 1991. Frequent detection of HIV-1 specific mRNAs in infected individuals suggest ongoing active viral expression in all stages of disease. AIDS Res. Human Retrov. 7: 361-367.

23. Schittman, S.M., J.J. Greenhouse, M.C. Psallidopoulos, M. Baseler, N.P. Salzman, A.S. Fauci, and H.C. Lane. 1990. Increasing viral burden in $\mathrm{CD}^{++}{ }^{+} \mathrm{T}$ cells in patients with human immunodeficiency virus (HIV) infection reflects rapidly progressive immunosuppression and clinical disease. Ann. Int. Med. 113: 438443.

24. Ho, D.D., T. Moudgil, and M. Alan. 1989. Quantitation of human immunodeficiency virus type 1 in the bloo of infected persons. N. Engl. J. Med. 321: 1621-1625.

25. Jackson, J.B., R.W. Coombs, K. Sannerud, F.S. Rhame, and H.H. Balfour. 1990. Rapid and sensitive viral culture method for human immunodeficiency virus type $1 . J$. Clin. Microbiol. 26: 1416-1418.

26. Gerken, G., P. Paterlini, M. Manns, C. Housset, S. Terre, H.-P. Dienes, G. Hess, W.H. Gerlich, P. Berthelot, K.H. Meyer zum Buschenfelde, and C. Brechot. 1991. Assay of hepatitis B virus DNA by polymerase chain reaction and its relationship to pre-S- and S-encoded viral surface antigens. Hepatology 13: 158-166. 
27. Kaneko, S., S. Murakami, M. Unoura, and K. Kobayashi. 1992. Quantitation of hepatitis C virus RNA by competitive polymerase chain reaction. J. Med. Virol. 37: 278-282.

28. Oka, S., K. Urayama, Y. Hirabayashi, O. Kiyokata, H. Goto, K. Mitamura, S. Kimura, and K. Shimata. 1990. Quantitative analysis of human immunodeficiency virus type 1 DNA in asymptomatic carriers using the polymerase chain reaction. Biochem. Biophys. Res. Commun. 167: 1-8.

29. Singer-Sam, J., M.O. Robinson, A.R. Belve, M.I. Simon, and A.D. Riggs. 1990. Measurement by quantitative PCR of changes in HPRT, PGH-1, PGK-2, APRT, Mtase, and Zfy gene transcripts during mouse spermatogenesis. Nucleic Acids Res. 18: 12551259.

30. Warren, W., T. Wheat, and P. Knudsen. 1991. Rapid analysis and quantitation of PCR products by high-performance liquid chromatography. BioTechniques 11:250255.

31. Langraf, A., B. Reckmann, and A. Pingoud. 1991. Quantitative analysis of polymerase chain reaction ( $\mathrm{PCR}$ ) products using primers labeled with biotin and a fluorescent dye. Anal. Biochem. 193: 231235.

32. Vary, C.P. 1992. Triple-helical capture assay for quantification of polymerase chain reaction products. Clin. Chem. 38: 687-694.

33. Ferre, F., A. Marchese, P.C. Duffy, D.E. Lewis, M.R. Wallace, H.J. Beecham, K.G. Burnett, F.C. Jensen, and D.J. Carlo. 1992. Quantitation of HIV viral burden by PCR in HIV seropositive Navy personnel represeting Walter Reed stages 1 to 6. AIDS Res. Human Retrovir. 8: 296-275.

34. Simmonds, P., P. Balfe, J.F. Peutherer, C.A. Ludlam, J.O. Bishop, and A.J. Leigh Brown. 1990. Human immunodeficiency virus-infected individuals contain provirus in small numbers in peripheral mononuclear cells at low copy numbers. J. Virol. 64: 864-872.

35. Brillanti, S., J.A. Garson, P.W. Tuke, C. Ring, M. Briggs, C. Masci, M. Miglioli, L. Barbara, and R.S. Tedder. 1991. Effect of $\alpha$-interferon therapy on hepatitis C viraemia in community acquired chronic non- $A$, non- $B$ hepatitis:A quantitative polymerase chain reaction study. J. Med. Virol. 34: 136-141.

36. Zhang, L.Q., P. Simmonds, C.A. Ludlam, and A.J. Leigh Brown. 1991. Detection, quantification and sequencing of HIV-1 from plasma of seropositive individuals and from factor VIII concentrates. AIDS 5: $675-681$.

37. Diviacco, S., P. Norio, L. Zentilin, S. Menzo, M. Clementi, G. Biamonti, S. Riva, A. Falaschi, and M. Giacca. 1992. A novel procedure for quantitative poly- merase chain reaction by coamplification of competitive templates. Gene 122: 30133020 .

38. Kellog, D.E., J.J. Sninsky, and S. Kwok. 1990. Quantitation of HIV-1 proviral DNA relative to cellular DNA by the polymerase chain reaction. Anal. Biochem. 189: 202-208.

39. Neubauer, A., B. Neubauer, and E. Liu. 1990. Polymerase chain reaction based assay to detect allelic loss in human DNA: Loss of $\beta$-interferon gene in chronic myelogenous leukemia. Nucleic Acids Res. 18: $993-948$.

40. Noonan, K.E., C. Beck, T.A. Holzmayer, J.E. Chin, J.S. Wunder, I.L. Andrulis, A.F. Gazdar, C.L. Wilman, B. Griffith, D.D. von Hoff, and I.B. Robinson. 1990. Quantitative analysis of MDR1 (multidrug resistence) gene expression in human tumors by polymerase chain reaction. Proc. Natl. Acad. Sci. 87: 7160-7164.

41. Gilliland, G., S. Perrin, K. Blanchard, and H.F. Bunn. 1990. Analysis of cytokine and mRNA and DBA:Detection and quantitation by competitive polymerase chain reaction. Proc. Natl. Acad. Sci. 887: 27252729.

42. Gilliland, G., S. Perrin, and H.F. Bunn. 1990. Competitive PCR for quantitation of mRNA. In PCR protocols. A guide to methods and applications (ed. M.A. Innis, D.H. Gelfand, J.J. Sninsky, and T.J. White).p. 60-69.Academic, San Diego.

43. Simon, L., R.C. Lévesque, and M. Lalonde. 1992. Rapid quantitation by PCR of endomycorrhizal fungi colonizing roots. $P C R$ Methods Applic. 2: 76-80.

44. Seibel, P., O. Mell, A. Hannemann, J. Muller-Hocker, and B. Kadenbach. 1991. A method for quantitative analysis of deleted mitochondrial DNA by PCR in small tissue samples. Methods Mol. Cell. Biol. 2: 147-153.

45. Menzo, S., P. Bagnarelli, M. Giacca, A. Manzin, P.E. Varaldo, and M. Clementi. 1992. Absolute quantitation of viremia in human immunodeficiency virus infection by competitive reverse transcription and polymerase chain reaction. J. Clin. Microbiol. 30: 1752-1757.

46. Becker-Andíe, M. and K. Hahlbrock. 1989. Absolute mRNA quantification using the polymerase chain reaction (PCR).A novel approach by a PCR aided transcript tritation assay (PATTY). Nucleic Acids Res. 17: 8437-9499.

47. Stieger, M., C. Demmoliere, J. AhlbornLaake, and J. Mous. 1991. Competitive polymerase chain reaction assay for quantitation of HIV-1 DNA and RNA. J. Virol. Methods 34: 149-160.

48. Henko, K. and M. Heibey. 1990. Quantitative PCR:the determination of the template copy numbers by temperature gradient gel electrophoresis (TGGE). Nucleic Acids Res. 18: 6733-6734.
49. Yerly, S., E. Chamot, B. Hirschel, and L.H. Perrin. 1992. Quantitation of human immunodeficiency virus provirus: Relationship with immunologic parameters. J. Infect. Dis. 166: 269-276.

50. Semple, M., C. Loveday, I. Weller, and R. Tedder. 1991. Direct measurement of viremia in patients infected with HIV-1 and its relationship to disease progression and zidovudine therapy. J. Med. Virol. 35: 38-45.

51. Scadden, D.T., Z. Wang, and J.E. Groopman. 1992. Quantitation of plasma human immunodeficiency virus type $1 \mathrm{RNA}$ by competitive polymerase chain reaction. J. Infect. Dis. 165: 1119-1123.

52. Bagnarelli, P., S. Menzo, A. Valenza, A. Manzin, M. Giacca, F. Ancarani, G. Scalise, P.E. Varaldo, and M. Clementi. 1992. Molecular profile of human immunodeficiency virus type 1 infection in symptomless and AIDS patients. J. Virol. 66: $7328-7335$.

53. Shindo, M., A.M. Di Bisceglie, R. Biswas, K. Mihalik, and S.M. Feinstone. 1992. Hepatitis $C$ virus replication during acute infection in the chimpanzee. J. Infect. Dis. 166: 424-427.

54. Ferre, F. 1992. Quantitative or semiquantitative PCR:Reality versus myth. $P C R$ Methods Applic. 2: 1-9. 


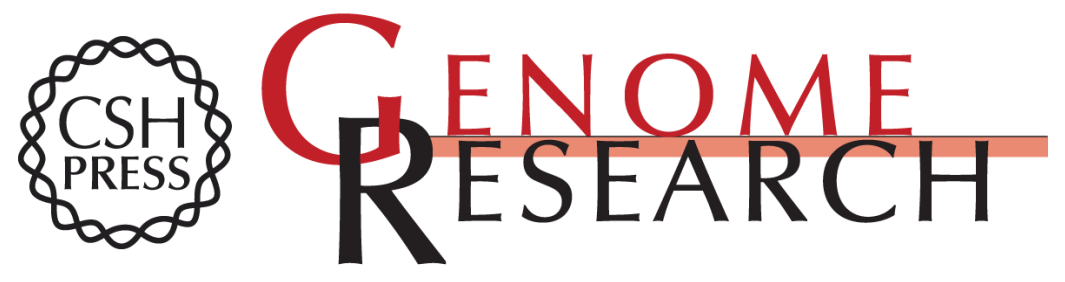

\section{Quantitative PCR and RT-PCR in virology.}

M Clementi, S Menzo, P Bagnarelli, et al.

Genome Res. 1993 2: 191-196

Access the most recent version at doi:10.1101/gr.2.3.191

References This article cites 51 articles, 12 of which can be accessed free at:

http://genome.cshlp.org/content/2/3/191.full.html\#ref-list-1

License

Email Alerting Receive free email alerts when new articles cite this article - sign up in the box at the Service top right corner of the article or click here.

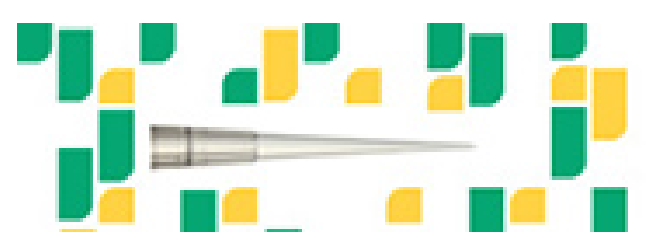

To subscribe to Genome Research go to: https://genome.cshlp.org/subscriptions 